\title{
Patient satisfaction with outpatient physical therapy in Saudi Arabia
}

\author{
Ghadah Algudairi ${ }^{1,2}$, Einas S. Al-Eisa ${ }^{2}$, Ahmad H. Alghadir ${ }^{2}$ and Zaheen Ahmed lqbal ${ }^{2^{*}}$ (1)
}

\begin{abstract}
Background: Patient satisfaction (PS) is a key measure of the quality and outcome of healthcare systems which reflects patients' experiences. The purpose of this study was to assess overall PS with outpatient physical therapy (PT) care in Saudi Arabia and identify associated characteristics and components.

Methods: Four hundred patients who received PT treatment during 2017 were invited to participate in this study. The MedRisk Instrument for Measuring Patient Satisfaction with Physical Therapy Care (MRPS) was used to assess PS.

Results: The average age of 358 (90\%) respondents was 38.1 (SD 12.7) years, and a majority (77\%) of them were female. At least $76 \%$ respondents reported feeling better after PT treatment, while the mean global satisfaction score of all respondents as per the MRPS was 3.56, indicating high satisfaction.

Conclusion: PT is still at an early stage of development in Saudi Arabia and is an integral part of the healthcare sector. PS is the key to identify areas for improvement and provide high quality healthcare to the public.
\end{abstract}

Keywords: Patient satisfaction, Physical therapy, Saudi Arabia

\section{Background}

Patient satisfaction (PS) is a multi-dimensional phenome non that reflects the patient's experiences while seeking healthcare [1]. It is directly associated with treatment outcomes and compliance with the treatment [2], and has been reported to be a key measure of quality and outcome of health care system [3, 4]. Patients who report higher satisfaction are often more likely to benefit from their treatment [5].

Outcome measures such as Physical Therapy Outpatients Survey (PTOPS) and the MedRisk instrument have been reported to be reliable and valid tools for measuring patient satisfaction with out-patient physical therapy services [6,7]. Various studies conducted around the world, have reported PS with various forms of treatment, including medical management, surgery, and physical therapy $[8,9]$. It has been related to various factors including patient age, their presenting condition, specific needs, expectations, previous experiences, social background, and personality $[2,4]$. However, due to cultural differences, the findings of these studies cannot be generalized

\footnotetext{
* Correspondence: zaiqbal@ksu.edu.sa; z_iqbal001@yahoo.com

${ }^{2}$ Rehabilitation Research Chair, College of Applied Medical Sciences, King

Saud University, Riyadh, Kingdom of Saudi Arabia

Full list of author information is available at the end of the article
}

and applied to the rest of the world. To the best of our knowledge, there have been no studies conducted in Saudi Arabia that report PS with physical therapy treatment.

The purpose of this study was to assess overall PS, as well as its components with outpatient physical therapy care in Saudi Arabia, to identify associated patient characteristics. The findings of this study can provide guidance for hospital managers to improve service quality and PS.

\section{Methods}

Four hundred patients who received physical therapy treatment for different conditions during 2017 were invited to participate in this study. The MedRisk Instrument for Measuring Patient Satisfaction with Physical Therapy Care (MRPS) was used to assess PS [7]. In addition, data on patients' demographics (age, gender, educational status, occupation) and clinical characteristics (treatment type and duration, pain, recovery) were also collected. The questionnaire was uploaded online and its web link along with an explanation of the study's purpose were sent to patients to invite them to participate in the study. The completion of the electronic survey was considered as consent for participation in the 
Table 1 Demographic and clinical characteristics among respondents $(N=358)$

\begin{tabular}{|c|c|c|c|c|c|}
\hline & & & & & \\
\hline & Number & Percentage & & Number & Percentage \\
\hline Age groups & & & Sport injuries & 25 & $7.1 \%$ \\
\hline$\leq 30$ & 120 & $33.5 \%$ & Women's Health & 16 & $4.5 \%$ \\
\hline $31-50$ & 187 & $52.2 \%$ & Others & 16 & $4.5 \%$ \\
\hline$>50$ & 51 & $14.2 \%$ & City of treatment & & \\
\hline Gender & & & Riyadh & 263 & $80.9 \%$ \\
\hline Male & 83 & $23.2 \%$ & Outside Riyadh & 62 & $19.1 \%$ \\
\hline
\end{tabular}

Educational status

Less than secondary $\quad 50$

Secondary 80

$14.0 \%$

College or higher

Occupation

$\begin{array}{ll}\text { Working } & 149 \\ \text { Student } & 64 \\ \text { Retired } & 36 \\ \text { Unemployed } & 109 \\ \text { Body parts treated } & \end{array}$

Neck and shoulder
Back
Upper limb
Lower limb
Multiple areas
Others

Time spent in the clinic (min)

0-15 min
16-30 min
$31-60 \mathrm{~min}$
$>60 \mathrm{~min}$

Pain duration in the body parts treated

Last 3 months

Last 6 months

Last year

30

Physical therapy treatment times during last year

$$
\begin{aligned}
& \text { This is the first time } \\
& 2-4 \text { times } \\
& >4 \text { times }
\end{aligned}
$$$$
114
$$$$
127
$$

Post treatment health status

$$
\text { Better }
$$$$
272
$$

No change

Worse

Physical therapy speciality

$$
\text { Musculoskeletal }
$$

Neurology

$\begin{array}{ll}237 & 66.9 \% \\ 60 & 16.9 \%\end{array}$

Table 1 Demographic and clinical characteristics among respondents $(N=358)$ (Continued)

study. Further, a reminder email was sent to the patients 2 weeks after uploading the questionnaire. Ethical approval was obtained from the institutional review board of our university before data collection.

\section{Data analysis}

The responses to the items and components of MRPS were coded on a 5-point Likert scale, with 5 indicating "complete satisfaction" and 1 indicating "complete non-satisfaction". Data were presented as frequencies and percentages for categorical variables and mean and standard deviation (SD) for continuous variables. SPSS software (release 23.0, Armonk, NY: IBM Corp) was used to test any statistical differences between the variables. The overall MRPS scores were compared using non-parametric tests: Mann-Whitney $\mathrm{U}$ test for two-group variables and Kruskal-Wallis test for more than two-group variables. The difference was considered significant if $p$ values were less than 0.05 .

\section{Results}

A total number of 358 (90\%) patients completed the survey. The average age of respondents was 38.1 (SD 12.7) years, and a majority (77\%) of them were female. The respondents reported that they sought physical therapy treatment for a variety of conditions, including musculoskeletal (67\%) and neurological (17\%) conditions. The affected body parts included the back (31\%), lower limbs (27\%), neck and shoulders (15\%) and upper limbs (15\%). At least $7 \%$ of the respondents reported they sought treatment for more than one body parts at a time. The average time spent by the majority of respondents (46\%) was $16-30 \mathrm{~min}$; at least $76 \%$ respondents reported feeling better after physical therapy treatment (Table 1).

\section{PS with physical therapy treatment in Saudi Arabia}

On the 5-point Likert scale used, in which 5 indicates maximum satisfaction, the mean global satisfaction score of all respondents for item 19 (Overall, I am completely satisfied with the services I receive from my therapist) was 3.56 (SD 1.21). Figure 1 shows the mean percentage of scores for individual components of the MRPS. The mean satisfaction for individual items ranged from 4.15 for item 10 (My therapist treated me respectfully) to 


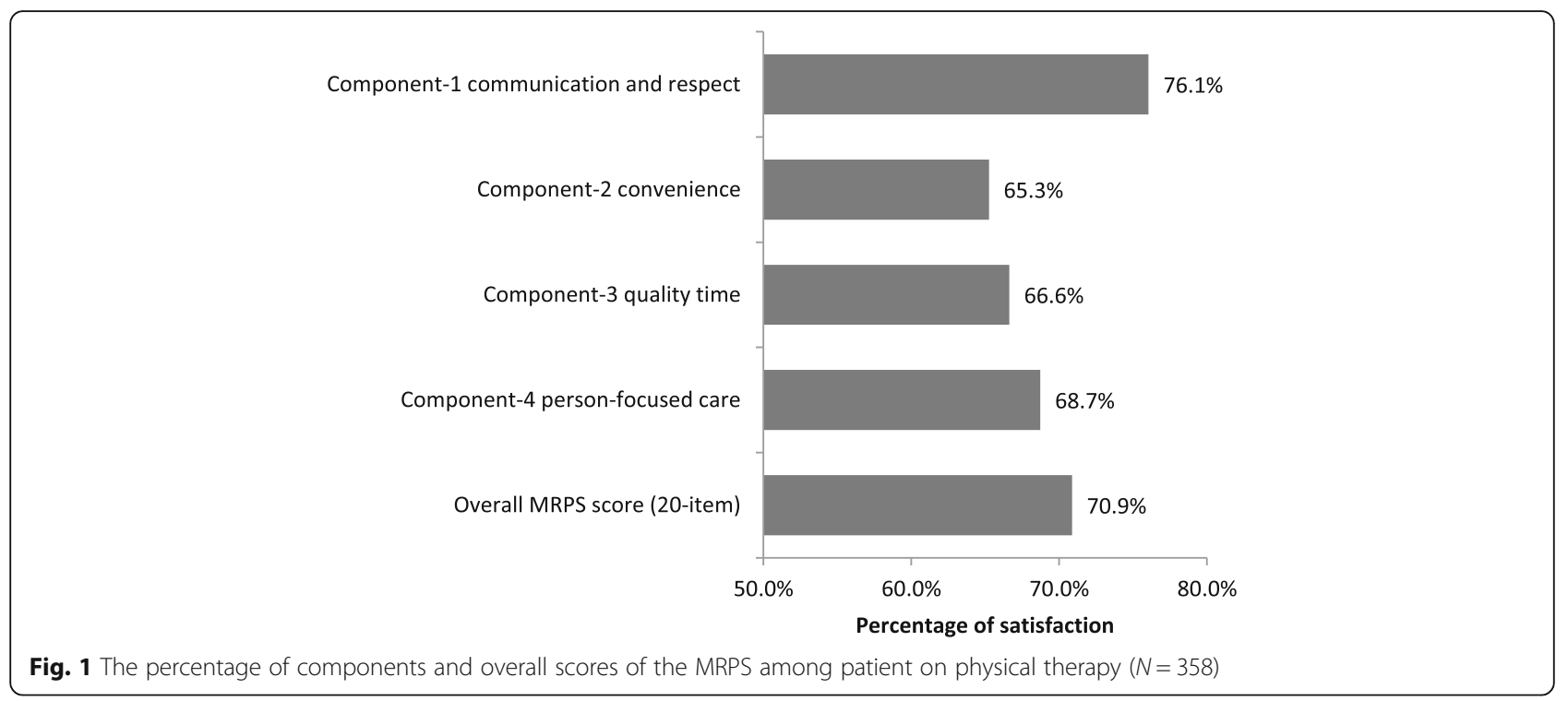

2.94 for item 5 (This office provided convenient parking) (Table 2).

No significant differences were found in the mean satisfaction scores on the basis of the body area being treated. Female respondents reported more satisfaction for the 'convenience' component of MRPS $(p<0.01)$. A significant relationship was observed between the mean satisfaction scores and age, educational status, occupation, time spent in clinic, number of times physical therapy treatment was sought in the last year, post treatment health status and area of clinic where treatment was sought $(p<0.05)$ (Table 3).

\section{Relation between individual components of MRPS and global satisfaction score}

Table 4 shows the correlations of different components of the MRPS with its global items [10,11] among respondents. All components (Communication and respect, Convenience, Quality time, and Person-focused care) significantly correlated with global satisfaction scores $(p<0.001)$.

\section{Discussion}

Hospitals in Saudi Arabia have recently been adopting different ways to ensure better health care for patients and meet accreditation standards [12]. For this purpose, it is necessary to have knowledge of patients' attitudes towards the quality of service provided by hospitals. PS has been reported to be a key outcome measure for assessing the quality and efficacy of hospital care [13, 14]. Despite the emphasis, no such research has been conducted to explore patients' perceptions related to physical therapy in the region. The present study aimed to determine PS with physical therapy treatment in Saudi Arabia. At least 76\% respondents reported feeling better after seeking physical therapy treatment, while the mean global satisfaction score of all respondents according to the MRPS was 3.56, indicating a high level of satisfaction.

MRPS has been widely used to report patient satisfaction with physical therapy treatment around the world [15]. Studies conducted in Brazil and Australia have reported high patient satisfaction with physiotherapeutic care (with mean score of 4.50 and 4.55 respectively) $[11,16]$. A patient is satisfied if their needs are fulfilled, and they have been provided with adequate information about their condition and treatment; hence, PS represents one aspect of treatment success [7]. In addition to the care outcome, patients' needs also relate to the quality of the treatment process [17]. Various studies have demonstrated that PS plays a role in patients' compliance with medical advice, follow up and even improvement in health status $[10,18,19]$. Therefore, PS with physical therapy is fast emerging as an outcome variable of critical importance [5].

Our results show high satisfaction among patients seeking physical therapy treatment in Saudi Arabia, irrespective of the nature of their condition and the body parts involved. Similar results were reported in studies conducted in various clinical settings across America, UK, Australia, and Europe, indicating high-quality care from physical therapy management across the world $[4,11,20-24]$. On the other hand, the overall satisfaction with PT was positively correlated with all components of PS, including communication and respect, convenience, quality time, and personal care. Perceptions about the quality of care are influenced by provider and patient interaction as well as the positive attitude of the therapist, in addition to their technical competence. Professionals who are warm and friendly generate higher levels of patients' satisfaction $[3,16]$. 
Table 2 Mean and SD of the items, components, and overall scores of the MRPS among respondents $(N=358)$

\begin{tabular}{|c|c|c|c|}
\hline & Number & Mean & SD \\
\hline Component-1 Communication and respect & 358 & 3.80 & 0.77 \\
\hline Item 1 The office receptionist was courteous & 351 & 3.66 & 0.98 \\
\hline Item 9 My therapist thoroughly explained the treatment(s) I received & 358 & 3.40 & 1.19 \\
\hline Item 10 My therapist treated me respectfully & 358 & 4.15 & 0.85 \\
\hline Item 11 The office staff was respectful & 352 & 4.05 & 0.89 \\
\hline Item 12 The therapist's assistant/aide was respectful & 328 & 3.95 & 0.88 \\
\hline Item 14 My therapist answered all my questions & 358 & 3.75 & 1.04 \\
\hline Item 15 My therapist advised me how to avoid future problems & 358 & 3.78 & 1.07 \\
\hline Item 18 My therapist gave me detailed home program instructions & 358 & 3.75 & 1.10 \\
\hline Component-2 Convenience & 358 & 3.26 & 0.64 \\
\hline Item 2 The registration process was appropriate & 358 & 3.64 & 0.98 \\
\hline Item 3 The waiting area was comfortable & 347 & 3.21 & 1.18 \\
\hline Item 4 The office location was convenient & 358 & 2.95 & 1.22 \\
\hline Item 5 This office provided convenient parking & 341 & 2.94 & 1.30 \\
\hline Item 6 I did not wait too long to see my therapist & 358 & 3.27 & 1.16 \\
\hline Item 7 The office hours were convenient for me & 358 & 3.56 & 1.06 \\
\hline Component-3 Quality time & 358 & 3.33 & 0.91 \\
\hline Item 6 I did not wait too long to see my therapist & 358 & 3.27 & 1.16 \\
\hline Item 8 My therapist spent enough time with me & 358 & 3.21 & 1.25 \\
\hline Item 13 My therapist listened to my concerns & 358 & 3.52 & 1.20 \\
\hline Component-4 Person-focused care & 358 & 3.44 & 0.95 \\
\hline Item 3 The waiting area was comfortable & 347 & 3.21 & 1.18 \\
\hline Item 16 The office and its facilities were clean & 358 & 3.75 & 1.06 \\
\hline Item 17 The office used up-to-date equipment & 358 & 3.35 & 1.19 \\
\hline \multicolumn{4}{|l|}{ Global items } \\
\hline Item 19 Overall, I am completely satisfied with the services I receive from my therapist & 358 & 3.56 & 1.21 \\
\hline Item 20 I would return to this office for future care & 358 & 3.49 & 1.25 \\
\hline Overall MRPS score (20-item) & 358 & 3.54 & 0.67 \\
\hline
\end{tabular}

Different studies from around the world have demonstrated higher levels of PS in the management of lower back pain with physical therapists than physicians. This is due to the interest in patients shown by physical therapists, shorter waiting time, and the actual time spent with the clinician and in counselling $[8,25]$. Physical therapists' friendly attitude, helpfulness, listening to the patients' concerns, and their understanding nature makes them more popular among patients [26].

Our results show that PS is associated with various factors including patients' gender, age, educational status, occupation, time spent in clinic, history of physical therapy treatment, outcome of treatment, and area of clinic where treatment was sought. Previous studies have also reported that patients' degree of satisfaction depends on various characteristics, including their race and gender $[6,27]$. Female patients reported higher satisfaction with physical therapy as compared to male patients $[4,26]$.
Patients who reported seeking physical therapy for acute musculoskeletal conditions reported higher satisfaction than those who sought physical therapy for chronic conditions [22, 28]. Additionally, there is some evidence that suggests older patients are more satisfied with physical therapy care $[4,26]$.

Study has shown that although there was moderate awareness about physical therapy among physicians in Saudi Arabia, referral of patients for physical therapy treatment depends on their specialty and work experience [29]. Other factors reported to affect PS also include the type of patient referring system [5]. Patients reported higher satisfaction when they received physical therapy through direct access instead of referral through physician $[3,30]$. People who received care through prepaid group practices reported to be less satisfied than those who received treatment through fee-for-service practice [6]. 
Table 3 Comparison of average component and overall scores of the MRPS and demographic and clinical characteristics among respondents $(N=358)^{a}$

\begin{tabular}{|c|c|c|c|c|c|}
\hline & $\begin{array}{l}\text { Component-1 Communication } \\
\text { and respect }\end{array}$ & $\begin{array}{l}\text { Component-2 } \\
\text { Convenience }\end{array}$ & $\begin{array}{l}\text { Component-3 } \\
\text { Quality time }\end{array}$ & $\begin{array}{l}\text { Component-4 Person- } \\
\text { focused care }\end{array}$ & $\begin{array}{l}\text { Overall MRPS score } \\
\text { (20-item) }\end{array}$ \\
\hline \multicolumn{6}{|l|}{ Age groups } \\
\hline$<=30$ & $3.90 \pm 0.73$ & $3.23 \pm 0.65$ & $3.47 \pm 0.82$ & $3.39 \pm 0.96$ & $3.58 \pm 0.63$ \\
\hline $31-50$ & $3.79 \pm 0.80$ & $3.31 \pm 0.64$ & $3.31 \pm 0.97$ & $3.51 \pm 0.93$ & $3.56 \pm 0.70$ \\
\hline$>50$ & $3.64 \pm 0.72$ & $3.17 \pm 0.61$ & $3.08 \pm 0.85$ & $3.29 \pm 0.95$ & $3.40 \pm 0.64$ \\
\hline P-value & 0.05 & 0.218 & 0.029 & 0.227 & 0.128 \\
\hline \multicolumn{6}{|l|}{ Gender } \\
\hline Male & $3.71 \pm 0.87$ & $3.02 \pm 0.74$ & $3.39 \pm 0.93$ & $3.26 \pm 1.09$ & $3.41 \pm 0.78$ \\
\hline Female & $3.83 \pm 0.73$ & $3.34 \pm 0.59$ & $3.32 \pm 0.91$ & $3.49 \pm 0.89$ & $3.58 \pm 0.63$ \\
\hline P-value & 0.637 & 0.001 & 0.423 & 0.153 & 0.22 \\
\hline \multicolumn{6}{|l|}{ Educational status } \\
\hline $\begin{array}{l}\text { Less than } \\
\text { secondary }\end{array}$ & $3.99 \pm 0.65$ & $3.36 \pm 0.58$ & $3.06 \pm 0.93$ & $3.71 \pm 0.94$ & $3.67 \pm 0.58$ \\
\hline Secondary & $3.88 \pm 0.74$ & $3.36 \pm 0.58$ & $3.26 \pm 0.93$ & $3.66 \pm 0.78$ & $3.63 \pm 0.62$ \\
\hline $\begin{array}{l}\text { College or } \\
\text { higher }\end{array}$ & $3.73 \pm 0.79$ & $3.21 \pm 0.67$ & $3.42 \pm 0.89$ & $3.30 \pm 0.98$ & $3.48 \pm 0.70$ \\
\hline P-value & 0.053 & 0.182 & 0.024 & 0.001 & 0.134 \\
\hline \multicolumn{6}{|l|}{ Occupation } \\
\hline Working & $3.69 \pm 0.83$ & $3.19 \pm 0.65$ & $3.37 \pm 0.93$ & $3.25 \pm 0.98$ & $3.46 \pm 0.73$ \\
\hline Student & $3.82 \pm 0.76$ & $3.09 \pm 0.67$ & $3.49 \pm 0.80$ & $3.26 \pm 0.93$ & $3.48 \pm 0.64$ \\
\hline Retired & $3.74 \pm 0.81$ & $3.30 \pm 0.63$ & $3.36 \pm 0.99$ & $3.74 \pm 0.64$ & $3.57 \pm 0.66$ \\
\hline Unemployed & $3.97 \pm 0.64$ & $3.45 \pm 0.59$ & $3.17 \pm 0.90$ & $3.69 \pm 0.92$ & $3.69 \pm 0.60$ \\
\hline$P$-value & 0.183 & 0.003 & 0.089 & $<0.001$ & 0.104 \\
\hline \multicolumn{6}{|l|}{ Body parts treated } \\
\hline $\begin{array}{l}\text { Neck and } \\
\text { shoulder }\end{array}$ & $3.89 \pm 0.69$ & $3.39 \pm 0.50$ & $3.44 \pm 0.86$ & $3.50 \pm 0.81$ & $3.64 \pm 0.57$ \\
\hline Back & $3.80 \pm 0.86$ & $3.32 \pm 0.64$ & $3.37 \pm 0.92$ & $3.38 \pm 1.00$ & $3.57 \pm 0.71$ \\
\hline Upper limb & $3.76 \pm 0.81$ & $3.21 \pm 0.68$ & $3.42 \pm 0.87$ & $3.32 \pm 1.10$ & $3.49 \pm 0.73$ \\
\hline Lower limb & $3.72 \pm 0.74$ & $3.14 \pm 0.72$ & $3.15 \pm 0.89$ & $3.47 \pm 0.95$ & $3.46 \pm 0.69$ \\
\hline Multiple areas & $4.13 \pm 0.53$ & $3.38 \pm 0.53$ & $3.43 \pm 1.25$ & $3.63 \pm 0.82$ & $3.73 \pm 0.60$ \\
\hline Others & $3.67 \pm 0.65$ & $3.15 \pm 0.63$ & $3.39 \pm 0.71$ & $3.49 \pm 0.66$ & $3.45 \pm 0.53$ \\
\hline$P$-value & 0.101 & 0.312 & 0.328 & 0.851 & 0.3 \\
\hline \multicolumn{6}{|c|}{ Time spent in the clinic (min) } \\
\hline $0-15 \min$ & $3.55 \pm 0.80$ & $3.20 \pm 0.61$ & $3.01 \pm 0.91$ & $3.28 \pm 0.95$ & $3.33 \pm 0.67$ \\
\hline $16-30 \mathrm{~min}$ & $3.80 \pm 0.78$ & $3.25 \pm 0.63$ & $3.41 \pm 0.87$ & $3.43 \pm 0.92$ & $3.56 \pm 0.68$ \\
\hline $31-60 \mathrm{~min}$ & $3.98 \pm 0.65$ & $3.34 \pm 0.68$ & $3.35 \pm 0.91$ & $3.55 \pm 0.96$ & $3.67 \pm 0.61$ \\
\hline$>60 \mathrm{~min}$ & $3.93 \pm 0.76$ & $3.24 \pm 0.68$ & $3.63 \pm 0.99$ & $3.53 \pm 0.97$ & $3.66 \pm 0.69$ \\
\hline P-value & 0.003 & 0.341 & 0.006 & 0.341 & 0.012 \\
\hline \multicolumn{6}{|c|}{ Pain duration in the body parts treated } \\
\hline Last 3 months & $3.92 \pm 0.72$ & $3.25 \pm 0.63$ & $3.44 \pm 1.01$ & $3.56 \pm 0.92$ & $3.64 \pm 0.67$ \\
\hline Last 6 months & $3.74 \pm 0.91$ & $3.16 \pm 0.76$ & $3.16 \pm 1.00$ & $3.29 \pm 1.06$ & $3.44 \pm 0.78$ \\
\hline Last year & $3.77 \pm 0.74$ & $3.29 \pm 0.62$ & $3.33 \pm 0.84$ & $3.42 \pm 0.92$ & $3.53 \pm 0.64$ \\
\hline P-value & 0.183 & 0.546 & 0.189 & 0.343 & 0.154 \\
\hline \multicolumn{6}{|c|}{ Physical therapy treatment times during last year } \\
\hline This is the first & $3.79 \pm 0.84$ & $3.25 \pm 0.68$ & $3.54 \pm 0.94$ & $3.36 \pm 1.00$ & $3.56 \pm 0.72$ \\
\hline
\end{tabular}


Table 3 Comparison of average component and overall scores of the MRPS and demographic and clinical characteristics among respondents $(N=358)^{a}$ (Continued)

\begin{tabular}{|c|c|c|c|c|c|}
\hline & $\begin{array}{l}\text { Component-1 Communication } \\
\text { and respect }\end{array}$ & $\begin{array}{l}\text { Component-2 } \\
\text { Convenience }\end{array}$ & $\begin{array}{l}\text { Component-3 } \\
\text { Quality time }\end{array}$ & $\begin{array}{l}\text { Component-4 Person- } \\
\text { focused care }\end{array}$ & $\begin{array}{l}\text { Overall MRPS score } \\
\text { (20-item) }\end{array}$ \\
\hline \multicolumn{6}{|l|}{ time } \\
\hline $2-4$ times & $3.83 \pm 0.72$ & $3.26 \pm 0.57$ & $3.19 \pm 0.88$ & $3.44 \pm 0.88$ & $3.54 \pm 0.63$ \\
\hline$>4$ times & $3.78 \pm 0.74$ & $3.28 \pm 0.69$ & $3.28 \pm 0.88$ & $3.50 \pm 0.96$ & $3.53 \pm 0.67$ \\
\hline P-value & 0.687 & 0.855 & 0.005 & 0.559 & 0.731 \\
\hline \multicolumn{6}{|c|}{ Post treatment health status } \\
\hline Better & $4.01 \pm 0.60$ & $3.36 \pm 0.61$ & $3.46 \pm 0.88$ & $3.62 \pm 0.86$ & $3.73 \pm 0.55$ \\
\hline No change & $3.25 \pm 0.83$ & $3.00 \pm 0.62$ & $2.87 \pm 0.88$ & $2.93 \pm 0.91$ & $3.04 \pm 0.65$ \\
\hline Worse & $2.87 \pm 0.88$ & $2.91 \pm 0.78$ & $3.03 \pm 0.89$ & $2.65 \pm 1.13$ & $2.76 \pm 0.77$ \\
\hline$P$-value & $<0.001$ & $<0.001$ & $<0.001$ & $<0.001$ & $<0.001$ \\
\hline \multicolumn{6}{|c|}{ Physical therapy specialty } \\
\hline Musculoskeletal & $3.79 \pm 0.75$ & $3.30 \pm 0.64$ & $3.35 \pm 0.95$ & $3.43 \pm 0.95$ & $3.55 \pm 0.67$ \\
\hline Neurology & $3.92 \pm 0.76$ & $3.23 \pm 0.61$ & $3.43 \pm 0.85$ & $3.48 \pm 0.88$ & $3.63 \pm 0.63$ \\
\hline Sport injuries & $3.78 \pm 0.80$ & $2.99 \pm 0.82$ & $3.16 \pm 0.64$ & $3.28 \pm 1.10$ & $3.40 \pm 0.74$ \\
\hline $\begin{array}{l}\text { Women's } \\
\text { Health }\end{array}$ & $3.51 \pm 0.97$ & $3.21 \pm 0.55$ & $3.10 \pm 0.78$ & $3.27 \pm 0.85$ & $3.35 \pm 0.67$ \\
\hline Others & $3.80 \pm 0.88$ & $3.24 \pm 0.61$ & $3.21 \pm 1.03$ & $3.50 \pm 1.05$ & $3.52 \pm 0.73$ \\
\hline$P$-value & 0.529 & 0.31 & 0.436 & 0.819 & 0.43 \\
\hline \multicolumn{6}{|l|}{ City of treatment } \\
\hline Riyadh & $3.86 \pm 0.78$ & $3.29 \pm 0.67$ & $3.37 \pm 0.92$ & $3.57 \pm 0.88$ & $3.60 \pm 0.68$ \\
\hline Outside Riyadh & $3.58 \pm 0.77$ & $3.11 \pm 0.52$ & $3.33 \pm 0.94$ & $2.97 \pm 1.05$ & $3.33 \pm 0.68$ \\
\hline P-value & 0.01 & 0.012 & 0.947 & $<0.001$ & 0.005 \\
\hline
\end{tabular}

${ }^{a}$ Data are presented as means and standard deviations, Non-parametric tests were used; Mann-Whitney test for two-group variables and Kruskal Wallis test for more than two-group variables

Significant $p$-values (bold) indicate that the component and overall scores are different between the categories of the variable

Previous studies have also linked PS with the type of hospital where treatment was sought [3]. In some countries, such as the USA, university hospitals are considered to provide better quality of care than other private and government hospitals [31]. Similarly, our study was also conducted in a university hospital showing higher patient satisfaction.

Healthcare access in Saudi Arabia has improved dramatically over the past three decades [12]. However, respondents from outside the capital city had lower satisfaction scores than those in the capital region. This difference may be due to cultural factors, or regional differences in health practices within a country [32]. In Saudi Arabia, the attitude of patients' and therapists' in rural regions differ from those in urban regions [33]. In order to generalize the findings, it is suggested that similar studies should be conducted in all regions of the country, and covering all types of hospitals and clinics.

\section{Limitations}

A self-report questionnaire was used for data collection, which increases the chances of respondents' over- or

Table 4 Correlations of different components of the MRPS with its global items $[10,11]$ among respondents $(N=358)$

\begin{tabular}{|c|c|c|c|c|}
\hline & \multicolumn{2}{|c|}{$\begin{array}{l}\text { Item } 19 \text { Overall, I am completely satisfied with the } \\
\text { services I receive from my therapist }\end{array}$} & \multicolumn{2}{|c|}{$\begin{array}{l}\text { Item } 20 \text { I would return to this office for } \\
\text { future care }\end{array}$} \\
\hline & Spearman Correlation Coefficient & $p$-value* & Spearman Correlation Coefficient & $p$-value ${ }^{*}$ \\
\hline Component-1 Communication and respect & 0.79 & $<0.001$ & 0.74 & $<0.001$ \\
\hline Component-2 Convenience & 0.50 & $<0.001$ & 0.50 & $<0.001$ \\
\hline Component-3 Quality time & 0.43 & $<0.001$ & 0.40 & $<0.001$ \\
\hline Component-4 Person-focused care & 0.61 & $<0.001$ & 0.60 & $<0.001$ \\
\hline
\end{tabular}


under-estimating their experiences. Positive response bias may also have affected our results. Participation in this study could have been limited as the present questionnaire based study and those who were not interested or didn't have time did not respond. This study could be repeated among a larger sample of patients representative of different parts of the country.

\section{Conclusion}

A key health service policy is currently being implemented in Saudi Arabia to adopt various methods for improving the quality of health care, and apply these methods across all health sectors to ensure an appropriate level of efficiency [12]. Our study indicates that knowledge about PS is necessary to identify areas that need improvement, and enable the availability of high-quality healthcare services to the public. Physical therapy is still at an early stage of development and documentation in Saudi Arabia [34]. As it is an integral player in the health care sector, patient feedback can be used systematically in order to improve health care.

\section{Acknowledgements}

The authors are grateful to the Deanship of Scientific Research, King Saud University for providing funding through the Vice Deanship of Scientific Research Chairs.

\section{Funding}

The authors are grateful to the Deanship of Scientific Research, King Saud University for providing funding through the Vice Deanship of Scientific Research Chairs.

Availability of data and materials

All related data has been presented within the manuscript.

\section{Authors' contributions}

The research idea and design were proposed by GA and AA. Review of literature was done by $\mathrm{ZI}$ and EE. Data collection and analysis were executed by $\mathrm{ZI}$ and GA. Manuscript preparation and submission was done by AA and EE. All authors have read and approved the manuscript.

\section{Ethics approval and consent to participate}

Ethical approval in accordance with the Declaration of Helsinki was obtained from the institutional review board of our university before data collection (Ref. KSU/RRC/49/02/2017). All participants were informed about the purpose and nature of this study, and completion of the electronic survey was considered to be consent for participation in the study.

\section{Consent for publication}

Not applicable.

\section{Competing interests}

The authors declare that they have no competing interests.

\section{Publisher's Note}

Springer Nature remains neutral with regard to jurisdictional claims in published maps and institutional affiliations.

\section{Author details}

${ }^{1}$ Physical Therapy Department, Security Forces Hospital, Riyadh, Kingdom of Saudi Arabia. ${ }^{2}$ Rehabilitation Research Chair, College of Applied Medical Sciences, King Saud University, Riyadh, Kingdom of Saudi Arabia.
Received: 26 November 2017 Accepted: 24 October 2018

Published online: 26 November 2018

\section{References}

1. Hudak PL, Wright JG. The characteristics of patient satisfaction measures Spine. 2000;25(24):3167-77.

2. Hills R, Kitchen S. Toward a theory of patient satisfaction with physiotherapy: exploring the concept of satisfaction. Physiother Theory Pract. 2007;23(5):243-54. https://doi.org/10.1080/09593980701209394.

3. Devreux ICN, Jacquerye A, Kittel F, Elsayed E, Al-Awa B. Benchmarking of patient satisfaction with physical rehabilitation services in various hospitals of Jeddah. Life Sci J. 2012;9(3):73-8.

4. Hush JM, Cameron K, Mackey M. Patient satisfaction with musculoskeletal physical therapy care: a systematic review. Phys Ther. 2011;91(1):25-36. https://doi.org/10.2522/pti.20100061.

5. Beattie PF, Pinto MB, Nelson MK, Nelson R. Patient satisfaction with outpatient physical therapy: instrument validation. Phys Ther. 2002;82(6): 557-65.

6. Roush SE, Sonstroem RJ. Development of the physical therapy outpatient satisfaction survey (PTOPS). Phys Ther. 1999;79(2):159-70.

7. Beattie P, Turner C, Dowda M, Michener L, Nelson R. The MedRisk instrument for measuring patient satisfaction with physical therapy care: a psychometric analysis. J Orthop Sports Phys Ther. 2005;35(1):24-32. https:// doi.org/10.2519/jospt.2005.35.1.24.

8. Skelton AM, Murphy EA, Murphy RJ, O'Dowd TC. Patients' views of low back pain and its management in general practice. Br J Gen Pract. 1996;46(404): 153-6.

9. Borkan J, Reis S, Hermoni D, Biderman A. Talking about the pain: a patientcentered study of low back pain in primary care. Soc Sci Med. 1995;40(7): 977-88.

10. Stewart MA. What is a successful doctor-patient interview? A study of interactions and outcomes. Soc Sci Med. 1984;19(2):167-75.

11. Hush JM, Yung V, Mackey $M$, et al. Patient satisfaction with musculoskeletal physiotherapy care in Australia: an international comparison. J Man Manip Ther. 2012;20(4):201-8. https://doi.org/10.1179/2042618612Y.0000000009.

12. Aljuaid M, Mannan F, Chaudhry Z, Rawaf S, Majeed A. Quality of care in university hospitals in Saudi Arabia: a systematic review. BMJ Open. 2016; 6(2):e008988. https://doi.org/10.1136/bmjopen-2015-008988.

13. Al-Doghaither AH. Inpatient satisfaction with physician services at King Khalid University Hospital, Riyadh, Saudi Arabia. East Mediterr Health J. 2004; 10(3):358-64.

14. Mokhtar SA, El Mahalli AA, Al-Mulla S, Al-Hussaini R. Study of the relation between quality of inpatient care and early readmission for diabetic patients at a hospital in the eastern province of Saudi Arabia. East Mediterr Health J. 2012;18(5):474-9.

15. Beattie PF, Nelson RM, Lis A. Spanish-language version of the MedRisk instrument for measuring patient satisfaction with physical therapy care (MRPS): preliminary validation. Phys Ther. 2007:87(6):793-800.

16. Medeiros FCD, Costa LOP, Oliveira NFC, Costa LCM. Satisfaction of patients receiving physiotherapy care for musculoskeletal conditions: a crosssectional study. Fisioterapia e Pesquisa. 2016;23(1):105-10.

17. Goldstein MS, Elliott SD, Guccione AA. The development of an instrument to measure satisfaction with physical therapy. Phys Ther. 2000;80(9):853-63.

18. Orton M, Fitzpatrick R, Fuller A, Mant D, Mlynek C, Thorogood M. Factors affecting women's response to an invitation to attend for a second breast cancer screening examination. Br J Gen Pract. 1991;41(349):320-2.

19. Fitzpatrick RM, Hopkins AP, Harvard-Watts O. Social dimensions of healing: a longitudinal study of outcomes of medical management of headaches. Soc Sci Med. 1983:17(8):501-10.

20. Beattie P, Dowda M, Turner C, Michener L, Nelson R. Longitudinal continuity of care is associated with high patient satisfaction with physical therapy. Phys Ther. 2005;85(10):1046-52.

21. Butler RJ, Johnson WG. Satisfaction with low back pain care. Spine J. 2008; 8(3):510-21. https://doi.org/10.1016/j.spinee.2007.04.006.

22. Hills R, Kitchen S. Satisfaction with outpatient physiotherapy: a survey comparing the views of patients with acute and chronic musculoskeletal conditions. Physiother Theory Pract. 2007;23(1):21-36. https://doi.org/10. 1080/09593980601147876.

23. Torstensen TA, Ljunggren AE, Meen HD, Odland E, Mowinckel P, Geijerstam S. Efficiency and costs of medical exercise therapy, conventional physiotherapy, and self-exercise in patients with chronic low back pain. A 
pragmatic, randomized, single-blinded, controlled trial with 1-year followup. Spine. 1998;23(23):2616-24.

24. Casserley-Feeney SN, Bury G, Daly L, Hurley DA. Physiotherapy for low back pain: differences between public and private healthcare sectors in Ireland--a retrospective survey. Man Ther. 2008;13(5):441-9. https://doi.org/10.1016/j. math.2007.05.017.

25. Overman SS, Larson JW, Dickstein DA, Rockey PH. Physical therapy care for low back pain. Monitored program of first-contact nonphysician care. Phys Ther. 1988;68(2):199-207.

26. Casserley-Feeney SN, Phelan M, Duffy F, Roush S, Cairns MC, Hurley DA. Patient satisfaction with private physiotherapy for musculoskeletal pain. BMC Musculoskelet Disord. 2008;9:50. https://doi.org/10.1186/ 1471-2474-9-50.

27. Hsieh MO, Kagle JD. Understanding patient satisfaction and dissatisfaction with health care. Health Soc Work. 1991;16(4):281-90.

28. Hills R, Kitchen S. Satisfaction with outpatient physiotherapy: focus groups to explore the views of patients with acute and chronic musculoskeletal conditions. Physiother Theory Pract. 2007;23(1):1-20. https://doi.org/10.1080/ 09593980601023705.

29. Al-Eisa ES, Al-Hogail H, Al-Rushud AS, et al. Awareness, perceptions and beliefs about physiotherapy held by physicians working in Saudi Arabia: a cross-sectional study. J Phys Ther Sci. 2016;28(12):3435-9. https://doi.org/10. 1589/jpts.28.3435.

30. Bush T, Cherkin D, Barlow W. The impact of physician attitudes on patient satisfaction with care for low back pain. Arch Fam Med. 1993;2(3):301-5.

31. Boscarino JA. The public's perception of quality hospitals II: implications for patient surveys. Hosp Health Serv Adm. 1992;37(1):13-35.

32. Algamdi SJ. Older patients' satisfaction with home health care services in AlBaha region. Saudi Arabia: University of Salford; 2016.

33. Mansour AA, al-Osimy MH. A study of satisfaction among primary health care patients in Saudi Arabia. J Community Health. 1993;18(3):163-73.

34. Alghadir A, Zafar H, lqbal ZA, Anwer S. Physical therapy education in Saudi Arabia. J Phys Ther Sci. 2015;27(5):1621-3. https://doi.org/10.1589/ jpts.27.1621

Ready to submit your research? Choose BMC and benefit from:

- fast, convenient online submission

- thorough peer review by experienced researchers in your field

- rapid publication on acceptance

- support for research data, including large and complex data types

- gold Open Access which fosters wider collaboration and increased citations

- maximum visibility for your research: over $100 \mathrm{M}$ website views per year

At $\mathrm{BMC}$, research is always in progress.

Learn more biomedcentral.com/submissions 